\title{
Identifying Information Technology Role towards Computerization of Land Administration in Nigeria
}

\author{
Bugi S. Z. \\ Pittsburg State University, \\ USA
}

\author{
Joshua John \\ Institute of Computing \& \\ ICT, Ahmadu Bello University, \\ Zaria - Nigeria
}

\author{
Amaku Amaku \\ Department of Computer Science, \\ College of ICT Salem University, \\ Lokoja \\ Kogi State, Nigeria
}

\begin{abstract}
This paper set out to identify the role of information technology towards computerization of land administration in Nigeria. The benefits of computerization is enormous as indicated in other countries of the world and the process demands retraining of staff of the ministry of land \& survey to be able to harness the benefits of a computerized system. A customized system should be the first steps towards obtaining a sustainable land administration system since it has to address the needs of Kaduna State specifically. Culture is part and parcel of Land administration system as such the culture of the people of Kaduna State must be considered in all Land matters. While recognizing the enormity of the work involved, it is imperative to note at this juncture that the benefits to be derived from a computerized land administration system is worth the trouble. This is because their expertise can be harnessed for a sustainable and enduring program design for use in land matters in the state. Websites are designed to facilitate easy processing of documents for organizations. In view of this, setting up a website for all land matters, including land application, processing, and allocation of land and issuance of certificate of occupancy $(\mathrm{C}$ of $\mathrm{O})$ is a venture that is not worth exploring, but a necessity.
\end{abstract}

\section{General Terms}

Land Administration, Information Technology, Remote Sensing and Wireless Network.

\section{Keywords}

Bandwidth, Ethernet, Topology, WiFi, WiMAX, ZigBee

\section{INTRODUCTION}

With the computerization of the economy, education, commerce engineering, etc. the role of information technology in land administration cannot be overemphasized. Most of the countries with a formal land information system in place such as western countries have already computerized their systems, or are in the process of doing so. The existing manual systems frequently limit the opportunities for implementing optimal solutions. Furthermore, the conversion of existing files and survey data requires huge resources. Countries building new land information systems from scratch-or almost-will have the benefit of not being restricted by existing systems, and should therefore have the possibility to implement optimal solutions from the very beginning. This should include the application of computer technology, both for textual data and for the maps.
Essential roles played by information technology in land administration which also, is tied to the benefits that accrues from a computerized land administration policy includes but not limited to:

i Guarantee ownership and security of tenure;

ii Support land and property taxation;

iii Provide security for credit;

iv Develop and monitor land markets;

v Protect State lands;

vi Reduce land disputes;

vii Facilitate land reform;

viii Improve urban planning and infrastructure development;

ix Support environmental management;

$\mathrm{x}$ Produce statistical data.

Introducing a new land administration system, including the implementation of formal land information registers, is a huge and time-consuming process. The importance of solid investigations and thorough planning cannot be underestimated [1].

It is important to stress that the development of related legislation, an improved organizational structure, financial mechanisms, and technical issues are closely interconnected. Experiences indicate that issues related to legislation, organization and funding are frequently more complex to solve than technical issues. These Guidelines recommend that countries in transition apply a step-by-step approach. Data content of the registers should initially be restricted to what is actually required to satisfy high-priority user needs. Demarcation and survey of boundaries are frequently a major element of the process. High geometric precision is often unnecessary for land administration. The possibility of applying low-cost surveying and mapping techniques should be investigated. (Hull et-et-al, 2007)

Although the most important issue for the land applicant is quick and efficient processing of land for which has been sought, there are other information that needs to be addressed. Every land applicant wants a fair deal for the land that has been requested. Commercial lands especially would want to get the land to be as appropriate and free from extra budgetary expenses. 
The following series of operations must be addressed when introducing a new land administration system:

i The determination of user needs

ii The creation of new administrative arrangements

iii The preparation of new legislation

iv The determination of what land and property rights already exist on the ground

v The demarcation and survey of new plots of land

vi The establishment of new registers and procedures for storing and retrieving land data

vii The setting in place of new financial management procedures

viii The development of public awareness as to how the system works [3].

\section{LITERATURE REVIEW}

\subsection{Performance}

Performance is central to the type of network that can be deployed for use in land administration. Each standard varies in geographical range, thus making one standard more ideal than the next depending on what it is one is trying to accomplish with a wireless network [9]. The performance of wireless networks satisfies a variety of applications such as voice and video. The use of this technology also gives room for expansions, such as from $2 \mathrm{G}$ to $3 \mathrm{G}$ and, most recently, $4 \mathrm{G}$ technology, which stands for fourth generation of cell phone mobile communications standards. As wireless networking has become commonplace, sophistication increases through configuration of network hardware and software, and greater capacity to send and receive larger amounts of data, faster, is achieved [10].

\subsection{Space}

Space is another characteristic of wireless networking. Wireless networks offer many advantages when it comes to difficult-to-wire areas trying to communicate such as across a street or river, a warehouse on the other side of the premise or buildings that are physically separated but operate as one [10]. Wireless networks allow for users to designate a certain space which the network will be able to communicate with other devices through that network. Space is also created in homes as a result of eliminating clutters of wiring [11]. This technology allows for an alternative to installing physical network mediums such as TPs, coaxes, or fiber-optics, which can also be expensive.

\subsection{Home}

For homeowners, wireless technology is an effective option compared to ethernet for sharing printers, scanners, and high speed internet connections. WLANs help save the cost of installation of cable mediums, save time from physical installation, and also create mobility for devices connected to the network [11]. Wireless networks are simple and require as few as one single wireless access point connected directly to the Internet via a router [8].

\subsection{Wireless Network Elements}

The telecommunications network at the physical layer also consists of many interconnected wireline Network Elements (NEs). These NEs can be stand-alone systems or products that are either supplied by a single manufacturer, or are assembled by the service provider (user) or system integrator with parts from several different manufacturers [23].

Wireless NEs are products and devices used by a wireless carrier to provide support for the backhaul network as well as a Mobile Switching Center (MSC).

Reliable wireless service depends on the network elements at the physical layer to be protected against all operational environments and applications (see GR-3171, Generic Requirements for Network Elements Used in Wireless Networks - Physical Layer Criteria) [12].

What are especially important are the NEs that are located on the cell tower to the Base Station (BS) cabinet. The attachment hardware and the positioning of the antenna and associated closures/cables are required to have adequate strength, robustness, corrosion resistance, and rain/solar resistance for expected wind, storm, ice, and other weather conditions. Requirements for individual components, such as hardware, cables, connectors, and closures, shall take into consideration the structure to which they are attached [21].

\subsection{DIFFICULTIES}

\subsubsection{Interference}

Compared to wired systems, wireless networks are frequently subject to electromagnetic interference. This can be caused by other networks or other types of equipment that generate radio waves that are within, or close, to the radio bands used for communication. Interference can degrade the signal or cause the system to fail.

\subsubsection{Absorption and Reflection}

Some materials cause absorption of electromagnetic waves, preventing it from reaching the receiver, in other cases, particularly with metallic or conductive materials reflection occurs. This can cause dead zones where no reception is available.

\subsubsection{Multipath Fading}

In multipath fading two or more different routes taken by the signal, due to reflections, can cause the signal to cancel out at certain locations, and to be stronger in other places (up-fade).

\subsubsection{Hidden Node Problem}

The hidden node problem occurs in some types of network when a node is visible from a wireless access point (AP), but not from other nodes communicating with that AP. This leads to difficulties in media access control.

\subsubsection{Shared Resource Problem}

The wireless spectrum is a limited resource and shared by all nodes in the range of its transmitters. Bandwidth allocation becomes complex with multiple participating users. Often users are not aware that advertised numbers (e.g., for IEEE 802.11 equipment or LTE networks) are not their capacity, but shared with all other users and thus the individual user rate is far lower. With increasing demand, the capacity crunch is more and more likely to happen. User-in-the-loop (UIL) may be an alternative solution to ever upgrading to newer technologies for over-provisioning.

\section{Capacity}

The capacity of a wireless network is determined by the channel.

\section{Channel}

Channel capacity in wireless communications 


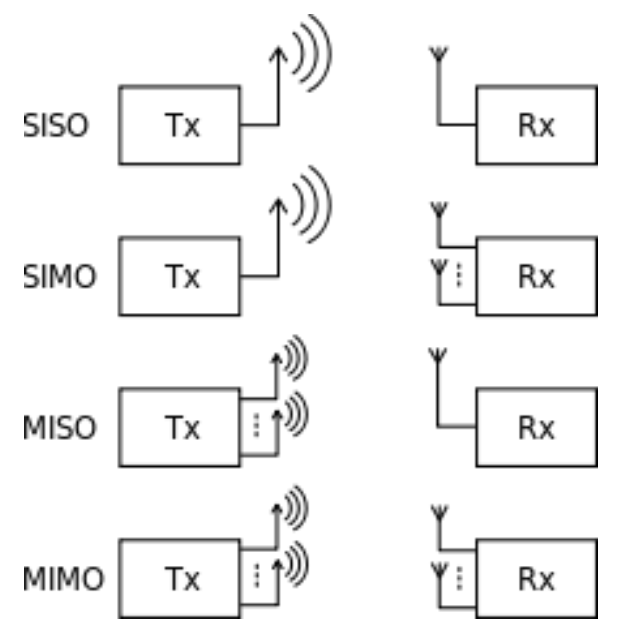

Understanding of SISO, SIMO, MISO and MIMO. Using multiple antennas and transmitting in different frequency channels can reduce fading, and can greatly increase the system capacity.

The maximum data rate of any single wireless link can be described by the Shannon's theorem which is related to the bandwidth in hertz, and the noise on the channel.

Network (Shannom, 2013)

\section{OBJECTIVE}

The total network bandwidth depends on how dispersive the medium is (more dispersive medium generally has better total bandwidth because it minimizes interference), how many frequencies are available, how noisy those frequencies are, how many aerials are used and whether directional antenna are in use, whether nodes employ power control and so on.

Cellular wireless networks generally have good capacity, due to their use of directional aerials, and their ability to reuse radio channels in non-adjacent cells. Additionally, cells can be made very small using low power transmitters, and this fact is used in cities to give network capacity that scales linearly with population density.

\subsection{Safety}

Wireless access points are also often close to humans, but the drop off in power over distance is fast, following the inversesquare law [13]. The position of the United Kingdom's Health Protection Agency (HPA) is that "...radio frequency (RF) exposures from WiFi are likely to be lower than those from mobile phones." It also saw "...no reason why schools and others should not use WiFi equipment."[14]. In October 2007, the HPA launched a new "systematic" study into the effects of Wi-Fi networks on behalf of the UK government, in order to calm fears that had appeared in the media in a recent period up to that time"[15]. Dr Michael Clark, of the HPA, says published research on mobile phones and masts does not add up to an indictment of WiFi [16]

\section{METHODOLOGY}

Computers are very often connected to networks using wireless links:

- Terrestrial microwave - Terrestrial microwave communication uses Earth-based transmitters and receivers resembling satellite dishes. Terrestrial microwaves are in the low-gigahertz range, which limits all communications to line-of-sight. Relay stations are spaced approximately $48 \mathrm{~km}(30 \mathrm{mi})$ apart.

- Communications satellites - Satellites communicate via microwave radio waves, which are not deflected by the Earth's atmosphere. The satellites are stationed in space, typically in geosynchronous orbit $35,400 \mathrm{~km}(22,000 \mathrm{mi})$ above the equator. These Earth-orbiting systems are capable of receiving and relaying voice, data, and TV signals.

- Cellular and PCS systems use several radio communications technologies. The systems divide the region covered into multiple geographic areas. Each area has a low-power transmitter or radio relay antenna device to relay calls from one area to the next area.

- Radio and spread spectrum technologies - Wireless local area networks use a high-frequency radio technology similar to digital cellular and a low-frequency radio technology. Wireless LANs use spread spectrum technology to enable communication between multiple devices in a limited area. IEEE 802.11 defines a common flavor of open-standards wireless radio-wave technology known as Wi-Fi.

- Free-space optical communication uses visible or invisible light for communications. In most cases, lineof-sight propagation is used, which limits the physical positioning of communicating devices.

\subsection{Types of Wireless Networks}

There are different types of wireless networks employed in land administration to enhance efficiency and provide solutions to the problems encountered, however not all are relevant. Some of the relevant ones are listed below.

\subsubsection{Wireless PAN}

Wireless personal area networks (WPANs) interconnect devices within a relatively small area that is generally within a person's reach [2]. For example, both Bluetooth radio and invisible infrared light provides a WPAN for interconnecting a headset to a laptop. ZigBee also supports WPAN applications [4]. Wi-Fi PANs are becoming commonplace (2010) as equipment designers start to integrate Wi-Fi into a variety of consumer electronic devices. Intel "My WiFi" and Windows 7 "virtual Wi-Fi" capabilities have made Wi-Fi PANs simpler and easier to set up and configure [5].

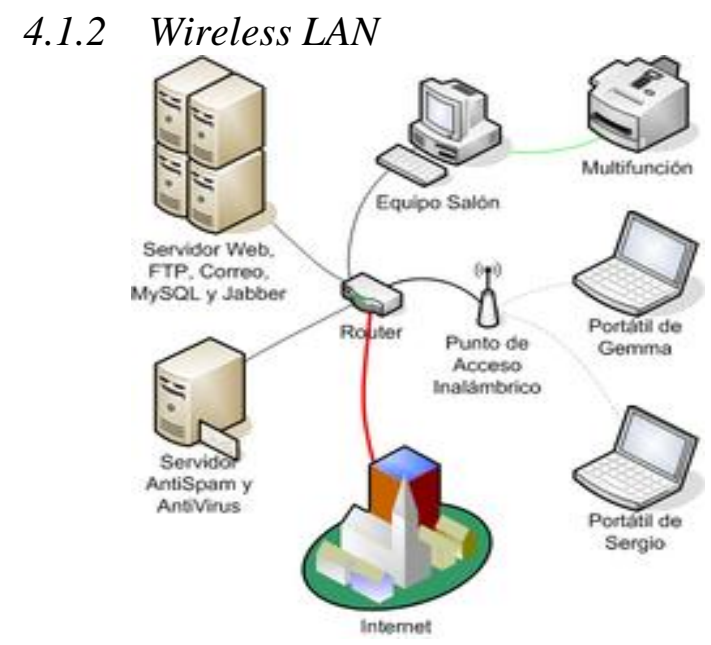


Wireless LANs are often used for connecting to local resources and to the Internet

A wireless local area network (WLAN) links two or more devices over a short distance using a wireless distribution method, usually providing a connection through an access point for Internet access. The use of spread-spectrum or OFDM technologies may allow users to move around within a local coverage area, and still remain connected to the network [24].

Products using the IEEE 802.11 WLAN standards are marketed under the Wi-Fi brand name. Fixed wireless technology implements point-to-point links between computers or networks at two distant locations, often using dedicated microwave or modulated laser light beams over line of sight paths. It is often used in cities to connect networks in two or more buildings without installing a wired link [20].

\subsubsection{Wireless Mesh Network}

A wireless mesh network is a wireless network made up of radio nodes organized in a mesh topology. Each node forwards messages on behalf of the other nodes. Mesh networks can "self-heal", automatically re-routing around a node that has lost power.

\subsubsection{Wireless MAN}

Wireless metropolitan area networks are a type of wireless network that connects several wireless LANs.

- WiMAX is a type of Wireless MAN and is described by the IEEE 802.16 standard [6].

\subsubsection{Wireless WAN}

Wireless wide area networks are wireless networks that typically cover large areas, such as between neighboring towns and cities, or city and suburb. These networks can be used to connect branch offices of business or as a public internet access system. The wireless connections between access points are usually point to point microwave links using parabolic dishes on the $2.4 \mathrm{GHz}$ band, rather than omnidirectional antennas used with smaller networks. A typical system contains base station gateways, access points and wireless bridging relays. Other configurations are mesh systems where each access point acts as a relay also. When combined with renewable energy systems such as photovoltaic solar panels or wind systems they can be standalone systems [19].

\subsubsection{Cellular Network}

Cellular networking is one of the most relevant networks required for land administration purposes since most of the operations are GPS oriented. The diagram below shows the type of cellular frequency reuse factor or pattern $1 / 4$ that is frequently deployed.

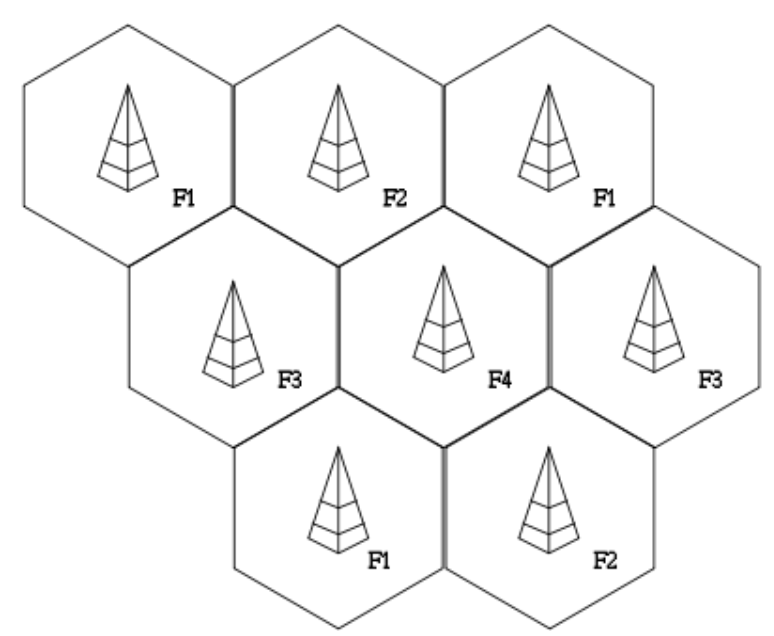

Example of frequency reuse factor or pattern 1/4

A cellular network or mobile network is a radio network distributed over land areas called cells, each served by at least one fixed-location transceiver, known as a cell site or base station. In a cellular network, each cell characteristically uses a different set of radio frequencies from all their immediate neighbouring cells to avoid any interference.

When joined together these cells provide radio coverage over a wide geographic area. This enables a large number of portable transceivers (e.g., mobile phones, pagers, etc.) to communicate with each other and with fixed transceivers and telephones anywhere in the network, via base stations, even if some of the transceivers are moving through more than one cell during transmission [25].

Although originally intended for cell phones, with the development of smartphones, cellular telephone networks routinely carry data in addition to telephone conversations:

- Global System for Mobile Communications (GSM): The GSM network is divided into three major systems: the switching system, the base station system, and the operation and support system. The cell phone connects to the base system station which then connects to the operation and support station; it then connects to the switching station where the call is transferred to where it needs to go. GSM is the most common standard and is used for a majority of cell phones [7].

- Personal Communications Service (PCS): PCS is a radio band that can be used by mobile phones in North America and South Asia. Sprint happened to be the first service to set up a PCS.

- D-AMPS: Digital Advanced Mobile Phone Service, an upgraded version of AMPS, is being phased out due to advancement in technology. The newer GSM networks are replacing the older system.

\subsubsection{Global Area Network}

A Global Area Network (GAN) is a network used for supporting mobile across an arbitrary number of wireless LANs, satellite coverage areas, etc. The key challenge in mobile communications is handing off user communications from one local coverage area to the next. In IEEE Project 802, this involves a succession of terrestrial wireless LANs [18]. 


\subsubsection{Space Network}

Space networks are networks used for communication between spacecraft, usually in the vicinity of the Earth. The example of this is NASA's Space Network.

\subsection{Different Uses}

Some examples of usage include cellular phones which are part of everyday wireless networks, allowing easy personal communications. Another example, Inter-continental network systems, use radio satellites to communicate across the world. Emergency services such as the police utilize wireless networks to communicate effectively as well. Individuals and businesses use wireless networks to send and share data rapidly, whether it be in a small office building or across the world [17].

\section{RESULTS}

\subsection{Major Findings}

$>$ The way we use land is influenced by our culture and customs.

$>$ Computerization of the economy, education, commerce engineering, etc. has made the role of information technology in land administration indispensable.

$>$ The existing manual systems frequently limit the opportunities for implementing optimal solutions in Land Administration system in Kaduna State.

$>$ Different sets of satellite data are analyzed by GIS computers to show the relationship between different land characteristics, such as relief or soil moisture.

$>$ Guarantee ownership and security of tenure; Support land and property taxation; Provide security for credit; Develop and monitor land markets.

> Protect State lands; Reduce land disputes; Facilitate land reform; Improve urban planning and infrastructure development.

$>$ Improve urban planning and infrastructure development; Support environmental management; Produce statistical data.

$>$ Land administration was found to be a process whereby land and the information about land may be effectively and efficiently managed [22]

$>$ Land administration was discovered to be a way in which the rules of land tenure are applied and made operational. Land administration, whether formal or informal, comprises an extensive range of systems and processes to administer land matters.

$>$ Presence of adequate data to drive the assessment procedure

$>$ Design of an IT program for the purpose of computerising land administration system in Kaduna State should be explored so that a customized computer program can be utilized for the efficiency of processing land matters in Kaduna State.

$>$ Experts in information technology should be shopped for to be engaged in the creation of a computerized data base for all land matters in Kaduna State.

$>$ Websites are designed to facilitate easy processing of documents for organizations. Setting up a website for all land matters, including land application, processing, and allocation of land and issuance of certificate of occupancy $(\mathrm{C}$ of $\mathrm{O})$ is a venture that is worth exploring.

$>$ Similarly, procurement of computerized land surveying equipment is necessary and the best equipment needs to be sought, as there are many in the market.

$>$ An enabling act by Kaduna State House of assembly

$>$ Design of a computer program for the purpose of computerising land administration system in the state

$>$ Creating a computerized data base for all land matters

$>$ Commencement of the conversion of old land information in Kaduna State into computerized format.

$>$ Setting up a website for all land matters, including land application, processing, allocation of land and issuance of certificate of occupancy ( $\mathrm{C}$ of $\mathrm{O})$

$>$ Procurement of computerized land surveying equipment.

\subsection{General}

In a general sense, wireless networks offer a vast variety of uses by both business and home users.

"Now, the industry accepts a handful of different wireless technologies. Each wireless technology is defined by a standard that describes unique functions at both the Physical and the Data Link layers of the OSI Model. These standards differ in their specified signaling methods, geographic ranges, and frequency usages, among other things. Such differences can make certain technologies better suited to home networks and others better suited to network larger organizations [19].

It is instructive to note that the role of information technology in land administration is very clear, important and necessary for efficient and hassle-free land administration. In England, for instance, the Land Utilisation Survey of the 1930s led to the Town and Country Planning Act of 1947. At this time, mapping techniques relied on direct observations made in the field, a time-consuming endeavor that produced quickly outdated surveys.

Aerial photography subsequently facilitated the production and improved the quality of land-use maps, but the most significant advances have been made since 1980. The introduction of remote sensing techniques and computerbased geographic information systems (GIS) has revolutionized land-use mapping and made it possible to gather large amounts of information quickly. Remote sensing relies on data collected by satellites such as the United States Landsat system and the French SPOT. These satellites orbit from pole to pole in about 100 minutes and repeatedly sense the surface of the planet rotating beneath them.

True color may sometimes be used, but the satellite images that yield the most detail are those created in false color using infrared radiation from the earth's surface. These images provide an almost instant 'map' of land use and are capable of revealing even short-term phenomena, such as a pollution event or the spread of crop disease. Different sets of satellite data are analyzed by GIS computers to show the relationship between different land characteristics, such as relief or soil moisture. These findings are then used to develop land capability indexes, which combine the relative importance of soil, microclimate, slope, and ground stability to give an assessment of the best use of a given piece of land [21] 
In the light of the foregoing, the role of information technology in land administration is very important and cannot be over emphasized. This will bring innovation and improvement in land administration in Kaduna State and Nigeria at large.

\section{CONCLUSION}

From the result of this study, therefore there is concluded that the use of the roles of ICT is yet to be exploited in Land administration system in Kaduna state as such the old system of processing land matters is still in vogue. It is concluded by this study that the role of ICT in Land Administration must be employed henceforth.

\section{RECOMMENDATION}

The study recommends that:

1. An enabling act by Kaduna State House of Assembly

2. Design of a computer program for the purpose of Computerising Land Administration System in the State.

3. Commencement of the conversion of old land information in Kaduna State into computerized format.

4. Creating a computerized data base for all land matters

5. Setting up a website for all land matters, including land application, processing, allocation of land and issuance of certificate of occupancy ( $\mathrm{C}$ of $\mathrm{O})$.

6. Procurement of computerized land surveying equipment.

More steps and sub-steps can be added as the process progresses.

Further studies: Due to the cosmopolitan nature of Kaduna State, a more robust and universal Land Administration System which can accommodate the status-quo and how to put it in place should be studied.

\section{REFERENCES}

[1] Land administration _en.wikipedia.org/wiki /Land_administration_For the present adoption of the Torrens system in the USA, see Justin T. Hull, .... up ${ }^{\wedge}$ Justin T. Holl, Jr., Peter Rabley, Mark Monacelli, David Ewan (2007)

[2] Wireless Networks: Bluetooth To Mobile Phones. Retrieved 8 August 2014.

[3] Reforming land and real estate markets (English)/ The ...documents.worldbank.org/.../2001/.../ reformingland-real-es...World Bank_Jun 30, $2001 \quad$ - Galal, Ahmed; Razzaz, Omar. 2001. Reforming land and real estate markets. Policy, Research working paper ; no. WPS2616. Washington, DC: ...

[4] Wireless Network Industry Report". Retrieved 8 July 2008.

[5] Wi-Fi Personal Area Networks get a boost with Windows 7 and Intel My WiFi". Retrieved 27 April 2010.

[6] Facts About WiMAX And Why Is It "The Future of Wireless Broadband. Retrieved 15 March, 2011
[7] GSM World statistics". GSM Association. 2010 Retrieved 16 March 2011.

[8] "Mobile Broadband Wireless connections (MBWA)". Retrieved 12 November 2011.

[9] Dean Tamara (2010). Network+ Guide to Networks (5th ed.). Boston: Cengage Learning. ISBN 978-1-42390245-4.

[10] Wireless LAN Technologies".Source Daddy web site. Retrieved 29 August 2011.

[11] WLAN Benefits". Wireless Center commercial web site. Retrieved 29 August 2011.

[12] GR-3171-CORE,Generic Requirements for Network Elements Used in Wireless Networks - Physical Layer Criteria

[13] Foster, Kenneth R (March 2007). "Radiofrequency exposure from wireless LANs utilizing Wi-Fi technology". Health Physics 92 (3): 280-289. doi:10.1097/01.HP.0000248117.74843.34. PMID 17293700.

[14] WiFi". Health Protection Agency. 26 October 2009. Retrieved 27 December 2009.

[15] Health Protection Agency announces further research into use of WiFi". Health Protection Agency. Retrieved 28 August 2008.

[16] Daniels, Nicki (11 December 2006). "Wi-fi: should we be worried?". The Times (London). Retrieved 16 September 2007.

[17] Wireless Networking in the Developing World: A practical guide to planning and building low-cost telecommunications infrastructure (2nd ed.). Hacker Friendly LLC. 2007. p. 425.

[18] Pahlavan, Kaveh; Levesque, Allen H (1995). Wireless Information Networks. John Wiley \& Sons. ISBN 0-47110607-0.

[19] Geier, Jim (2001). Wireless LANs. Sams;. ISBN 0-67232058-4.

[20] Goldsmith, Andrea (2005). Wireless Communications. Cambridge University Press. ISBN 0-521-83716-2.

[21] Pahlavan, Kaveh; Krishnamurthy, Prashant (2002). Principles of Wireless Networks - a Unified Approach. Prentice Hall. ISBN 0-13-093003-2.

[22] Rappaport, Theodore (2002). Wireless Communications: Principles and Practice. Prentice Hall. ISBN 0-13042232-0.

[23] Rhoton, John (2001). The Wireless Internet Explained. Digital Press. ISBN 1-55558-257-5.

[24] Kostas Pentikousis (March 2005). "Wireless Data Networks". Internet Protocol Journal 8 (1). Retrieved 29 August 2011.

[25] Pahlavan, Kaveh; Krishnamurthy, Prashant (2009). Networking Fundamentals - Wide, Local and Personal Area Communications. Wiley. ISBN 978-0-470-99290-6 